\title{
An investigation of the factors affecting relationship marketing(RM) and the satisfaction of key customers (A Case Study: key Customers of Saderat Bank)
}

\author{
Ali Sanayei ${ }^{{ }^{*}}$, Elham sahami $^{2}$ \\ ${ }^{l}$ Department of management, Faculty of administrative Sciences and economic, \\ University of Isfahan, Isfahan, Iran \\ ${ }^{2}$ Payam Noor University, Karaj \\ *Corresponding author E-mail:Drsanayei@gmail.com
}

\begin{abstract}
Today, using marketing methods based on an mix of services(7P)and application of promotion tools which are easily imitable for all banks is not responding in the totally competitive and changing environment of financial institutions. Therefore, most of successful banks in the world, along with the the application of customer-oriented strategies have started to use relationship marketing based on the establishment and maintenance of a long term relationship with customers. The present study, regarding the importance of the current issue, investigated the effect of four social factors, quality of services, information interchange and Monitor relationships and their effects on the satisfaction of key customers of Saderat Bank. The data were accumulated through questionnaires and analyzed by the tests of regressionand Pearson \& Friedman correlation coefficient. The ANOVAs table and analyses of hypotheses confirmed the four research hypotheses. Based on the results, the services factor was placed on the top having the largest correlation coefficient followed with the factors of information exchange, supervision of relationships and social factor which indicated a positive significant relationship with customers satisfaction.
\end{abstract}

Keywords: Banking services, key customers, relationship marketing, satisfaction

\section{Introduction}

Today due to accelerating changes and appearance of new technologies, different services like the Internet and financial cellphone softwares are quickly copied by competitors because they (services) don't have copyright or patent. This shows the importance of relationship marketing (RM) since providing new services is greatly threatened by the rivals and a stronger factor, instead of new services, should fulfill loyalty and satisfaction of customers. Moreover, regarding the privatization of many governmental banks, and the trivial difference of the bank's profit in the section of the attraction of resources and consumptions to achieve a stable Competitive advantage, the acceptance of the new paradigm of marketing concept " the relationship marketing " is inevitable.

However, the challenge is to understand how to manage RM a cost effective way so that a long term relationship and satisfaction be established in a cost effective way to result in more profitability [14].

Through the past decades, many organizations have understood the importance of customer satisfaction in that Maintaining the existing customers costs less than finding new ones. Furthermore, the maintance and Increased of customer satisfaction has become a very important operational objective in most organizations.Besides, the intensity of competition in the current markets and the importance of keeping the customers has caused the organizations to gradually step toward the establishment, maintenance and improvement of their relationship with customers. Based on literature, "relationship marketing" is among the best methods in this regard.

Companies have found out that losing a customer is more than merely losing a deal, rather it means losing the whole flow of purchase which the customer brings them in the trade period or lifetime[7].However, according to the marketing manager of Bank-One , merely $5 \%$ of customers consist $100 \%$ of profitability sources [2].

Furthermore, Reichhald and Sasser claimed that a 5\% increase in customer maintenance rate, based on the industry type leaded to a $25-85 \%$ profitability increase( In terms of net worth ) [10]. 
The important and effective researches of SasrovichHeld(1990) also showed that the profitability rate of banks goes beyond $85 \%$ with every $5 \%$ increase in the customers maintenance rate [11]. In practice, relationship marketing is a different form of other types of marketing and it's the understanding of the value of long term relationships with customers and the expansion of relationships instead of using repetitive ads and promotion messages. The perspective of relationship marketing is founded on this belief that on the pick of the values of exchanging products and services, the existing relationship between two parties brings about an added value for customers and other suppliers and providers[5]. Besides when the trading parties are committed to each other, there is more tendencies to cooperation, fulfillment of the trade pal's needs, information sharing and problem solving. [13] .In most definitions, the relationship marketing is introduced as a "process" toward which all the marketing activities should be directed[5]. This three-stage process consists of communications, interactions and creations of value. Gummesson (1993) defined the term as a strategyin which the management of interactions, relationships and networks is a fundamental issue.

According to Gro"nroos (1994), the aim of relationship marketing is to establish,

maintain, and enhance relationships with customers and other partners, at a profit, so that the objectives of the parties involved are met.

The development of relationship marketing points to an important change in the principles of marketing: changing from competition and quarrel to cooperation. Following the extension of such paradigm, financial institutions due to working in challenging environments have been compelled to change their reaction method against the market in a way to focus less on products and more on customers and have a long-term perspective instead of a short-term one. [9].

Finally, to render a clear image of the relationship marketing concept, we provide one of the most comprehensive definitions in the literature of relationship marketing by Gro"nroos: "Marketing from a relational perspective can beendefined as the process of managing the firm'smarket relationships [5],or moreexplicitly as the process of identifying andestablishing, maintaining, enhancing, and whennecessary terminating relationships withcustomers and other stakeholders, at a profit, sothat the objectives of all parties involved are met,where this is done by a mutual giving andfulfillment of promises [5].

\section{Literate review}

\subsection{Background research}

A range of online databases were searched to review the literature on RM.this provides a literature review and bibliography of RM literature for the twelve-year period. Only, 209 papers had RM as the primary research topic.The contribution of research papers has been on the rise across the time frame and there has been a sharp rise in RM research publication in the recent years. In addition, there were a lot of research papers in the online databases pertaining to privacy, cultural impact, impact of gender, impact of technology, impact of societal marketing, etc. These were classified as issues as they represented topics which will be directly impacted by or having an impact on RM.Further, RM research has involved services as well as goods and business-to-business segment, though the concentration is clearly biased towards services. Also, research has been largely concentrated in countries like the UK, the USA and China. In fact, there are too many countries which have not witnessed any significant RM research activity. Therefore, studies should also be done in the context of these countries to further test the external validity of the various conceptual or implementation models. [3]

\subsection{Customers satisfaction and relationship marketing}

The satisfaction of customers is the main factor of success in most organizations. Most studies have pointed to arelationship between customers satisfaction and face to face contact, further purchase loyalty and profitability increase. [4]. So far different definitions have been suggested regarding the concept of customer satisfaction. Each of these definitions approaches the concept from a different perspective. All the present definitions about satisfaction describe it as a process. These definitions consider the key variables and mechanisms for the interaction of the variables and believe that satisfaction is the final stage of a psychological process.

Philip Cotler defines satisfaction as "the person's pleasant or unpleasant feelings created by the comparison of the product's performance in relation to the consumer's expectations."

In this definition the customer satisfaction depends on product performance and his expectations.(The provided questionnaire for this research studies satisfaction based on Kotler's definition paying special attention to customer expectations). 
If the product's performance is more than expectations we will have Very pleased customer or in other words, be happy. The client who is satisfied with the provided product tends less to change his seller and will be happier with his purchase. This makes too much sense as well as an affective dependence which itself leads loyalty. Accordingly it is now widely accepted that customer satisfaction leads to loyalty.

However in relation to satisfaction we must note that as it was said, satisfaction depends on mental performance and expectations. Hence the marketers should take care to behave in a way not to increase the level of customer satisfaction higher than the company's capabilities to prevent satisfaction.

\subsection{The relationship marketing model of "So, S. "and "Speece"}

In this study We applied the model presented by professor Stella Manso and Mark Speece which was used to specify the factors of relationship marketing in Chinese and foreign banks in Hong Kong. The privilege of this model is the inclusion of social activities which are in adaptable with the environment of Asian and developing countries. The researchers of the present study applied changes and reforms to this model.

Man sue and Space classified the factors of relationship marketing into four categories as the following:

1. Social activity ( such as inviting customers to have lunch or dinner with them, and arranging formal meetings with customers).

2. Sales activity ( such as introducing new products)

3. Monitor relationships ( maintaining the relationships between the organization and customers)

4. Information exchange (such as sending the publications and the research results' information to the customers) [12].

Since in this research the bank services were studied, the factor of services quality was replaced with sales activity.

\section{Methodology}

\subsection{Research method}

In this research we tried to specify the factors affecting relationship marketing, based on the environment and the dominant culture in the branches of Saderat Bank and study the role of relationship marketing in fulfilling the satisfaction of key customers in this bank.

\section{Hypotheses:}

1. The social factors can affect the satisfaction of the key customers of Saderat bank.

2. The factor of quality of services can affect the satisfaction of the key customers of Saderat bank.

3. The factor of the Information exchange with customers can affect the satisfaction of the key customers of Saderat bank.

4. The factor of monitor on the relationship of the bank with customers can affect the satisfaction of the key customers of Saderat bank.

\subsection{Population and sampling}

Population is limited to the key customers of Saderat bank. Based on the definition of Key customer and regarding the inhomogeneity of branches in case of quality, sampling was done by a combination of two methods of random and stratified sampling[1] in a way that the population divides into homogenous groups including of branches : superior first rate, second rate, third and fourth rate. Since there is the possibility of existing samples (of key customers) in different branches, in a way that the possibility of existing a key customer in superior and first rate branches is high and the number of key customers in the fourth and fifth rate branches is rare relative weight appropriate for these possibilities would be assigned to each homogenous group. For instance, for the superior and first rate branches, a weight of 0.7 is assigned and regarding the number of branches, in each group in average, 4 key customers are selected randomly.

\subsection{Data analysis}

\subsubsection{Pearson test}


To determine the relation between the factors of relationship marketing and satisfaction we used the Pearson significance coefficient. In this article, only the test of the first hypothesis is described in detail and the summary and test results of the other three hypotheses are shown in the table.

$\mathrm{H}_{0}: \rho=0$ There is no significant relationship between social activities and the key customers' satisfaction

$\mathrm{H}_{1}: \rho \neq 0$ There is a significant relationship between social activities and the key customers' satisfaction. [8]

Table 1: Pearson test results for the first hypothesis

\begin{tabular}{|c|c|c|c|}
\hline Test results & Std. Error & Sig. (2-tailed) & R Pearson Correlation \\
\hline reject $\mathrm{H}_{0}$ Hypotheses confirm & 0.005 & 0.007 & 0.239 \\
\hline
\end{tabular}

Since the significance level is lower than the error level, the hypothesis $\mathrm{H}_{0}$ is rejected in the error level of 0.95 . This means that there is a significance relationship between social factors and customer satisfaction. The estimated $\boldsymbol{r}$ also indicates the correlation coefficient.

Table 2: Pearson test results for the hypothesis

\begin{tabular}{|c|c|c|c|c|}
\hline Test results & Std. Error & Sig & R & Hypotheses \\
\hline hypotheses confirm & 0.05 & 0.007 & 0.239 & social factors \\
\hline hypotheses confirm & 0.05 & 0.000 & 0.815 & Services quality \\
\hline hypotheses confirm & 0.05 & 0.000 & 0.243 & Informatione interchange \\
\hline hypotheses confirm & 0.05 & 0.000 & 0.753 & Monitor relationships \\
\hline
\end{tabular}

Since the significance level in all four hypotheses is less than the error level, all four hypotheses confirm a determined relation between factors affecting the relationship marketing and satisfaction.

\subsubsection{The regression test:}

This method aims at testing the relationship between independent variables including the factors of relationship marketing ( social, information exchang, quality of services and monitor relationships) on dependent variable of satisfaction.

\section{Variance analysis test:}

$\mathrm{H}_{0}$ : There is no determined relationship between (social factor and satisfaction) variables.

$H_{1}$ :There is a determined relationship between ( social factor and satisfaction) variables.

Table 3: ANOVA table for the first hypothesis

\begin{tabular}{|c|c|c|c|c|c|}
\hline & Sum of Squares & Df & Mean Square & F & Sig \\
\hline Regression & 10.049 & 1 & 10.049 & 7.449 & 0.007 \\
\hline Residual & 166.152 & 124 & 1.340 & & \\
\hline Total & 176.201 & 125 & & & \\
\hline
\end{tabular}

Based on the ANOVA table, since the estimated significant level for F statistic in all variables is lower than the error level, the data don't confirm $\mathrm{H}_{0}$ and therefore $H_{1}$ is confirmed. Hence the existence of a relationship between the independent variable of social factor and the dependent variable of satisfaction is confirmed.( sig level $\leq 0.05)$ Due to the bulk of data in tables and the stages of the variance analysis test, the test results derived from the ANOVA table of each hypothesis are described in summary in the below table.

Table 4: Summary ANOVA table for the hypothesis

\begin{tabular}{|c|c|c|c|c|c|}
\hline Test results & $\begin{array}{c}\text { Mean } \\
\text { Square }\end{array}$ & F & $\begin{array}{c}\text { Std. } \\
\text { Error }\end{array}$ & Sig & hypotheses \\
\hline hypotheses confirm & 13.475 & 16.424 & 0.05 & 0.000 & information interchange \\
\hline hypotheses confirm & 23.116 & 245.359 & 0.05 & 0.000 & Services quality \\
\hline hypotheses confirm & 38.283 & 161.998 & 0.05 & 0.000 & Monitor relationships \\
\hline
\end{tabular}

In all of these tests, as the significant level is lower than the error level, the research hypotheses confirm the existing relationship between factor affecting on relationship marketing and customer satisfaction. 
Table (10) the rating mean of customer satisfaction for each factor

\subsubsection{Regression test and linear regression model}

$\mathrm{H}_{0}: \beta=0$ There is no significant and positive relationship between social factors and satisfaction. .

$H_{1}: \beta \neq 0$ There is a significant and positive relationship between the independent variable of social factors and satisfaction .

Table 5: regression test results for the first hypothes

\begin{tabular}{|c|c|c|c|c|}
\hline Sig & $\boldsymbol{R}^{\mathbf{2}}$ & $\mathbf{R}$ & Independent variable B & Dependent variable \\
\hline 0.007 & 0.57 & 0.49 & $\begin{array}{c}\text { Constant factor. 1.694 } \\
.151 \text { social factor }\end{array}$ & Satisfaction \\
\hline
\end{tabular}

If the significance level of $\mathrm{T}$ in all variables is smaller than 0.05 the null hypothesis will be rejected and we can conclude that the social factors affect satisfaction.

The regression model provided by the effect of social factors using the above table:

Customer satisfaction $=1.694+(0.151)$ ( social factor)

The linear regression model provided by the effect of information interchange:

Customer satisfaction $=1.528+(0.267)$ (information interchange )

The regression model provided by the effect of Services quality factors :

Customer satisfaction $=0.124+(1.159-)$ (Services quality)

The regression model provided by the effect of monitor relationships factors

Customer satisfaction $=0.482+(0.768)($ monitor relationships $)$

\subsubsection{Friedman test for factors' rating}

To test the equality of the rating of customer satisfaction of the main criteria, the Friedman Variance analysis test was applied. [8]

$\mathrm{H}_{0}$ :The rating of customer satisfaction regarding each of the four factors is equal.

$H_{1}$ :There is a significant difference between at least two of the ratings of customer satisfaction regarding the four criteria.

Table 6: Friedman test results

\begin{tabular}{|c|c|c|c|c|}
\hline Test results & Std error & Sig & Df & Statistic F \\
\hline $\mathrm{H}_{0}$ reject & 0.05 & 0.000 & 3 & 48.658 \\
\hline
\end{tabular}

Since the significant level is lower than the error level of 0.05 it can be inferred that the sample data don't yield a strong proof for the acceptance of $\mathrm{H}_{0}$. Hence it can be concluded that the satisfaction of customers regarding each factor is not equal and the factor of services quality is more important compared to other factors.

Table 7: the rating mean of customer satisfaction for each factor

\begin{tabular}{|c|c|c|}
\hline Mean Rank & Variables & Rating \\
\hline 2 & Services quality & 1 \\
\hline 2.34 & information interchange & 2 \\
\hline 2.56 & monitor relationships & 3 \\
\hline 3.10 & Social factors & 4 \\
\hline
\end{tabular}

\section{Conclusion and recommendations}

Based on the analysis of data all the four research hypotheses were confirmed. Regarding the Pearson correlation coefficient and the Friedman test we found out that the most effective factor in customer satisfaction was related to the quality of services and the lest effective factor was related to social factors. In the following some suggestions for each factor are mentioned discretely. 


\subsection{Social factors}

Since the most effective factor among the testing elements of social factors in relation to customer satisfaction was friendly meetings with the branch manager the bank is suggested to pay more attention to select capable and skill managers to establish strong relationships with customers. In addition, it's suggested that the organization's culture be changed in order to reinforce close social connections to improve relationships and maintain key customers. The obtained results show that informal and out of place relationships with branch managers have little effect on the increase of relationships and cooperation with the bank. This fact may originate from our Islamic-Iranian culture in that our official system dispraise unauthorized relationship out of the workplace and legal limitations.

\subsection{The factors of information interchange}

From the standpoint of customers to be informed of new services constantly and regularly leads to customer satisfaction in an acceptable level. Therefore the bank is recommended to have a clear plan to announce the new services to customers by appropriate means such as SMS, brochures, ads or directly by the bank's experts. Moreover, along with providing the information, banks can do the suggested activities as the following:

- Establishing an appropriate place in the branch for the meeting of bank's experts with key customers;

- Providing a regular plan for the meeting of bank's experts with key customers;

- Giving useful information with economic justification;

- Suggestions for new founding in order to help the key customers and dicrease his costs;

- Due to the important role of providing useful information by banks in the fulfillment of customer satisfaction and increase of relationships, banks should employ experts or help the current staff empowerment .

\subsection{The factors of quality of services}

In this regard, the staff's role is most noticeable from the customers' viewpoint. The factors of contact, proficiency and capability of staff in dealing with key customers are closely connected to relationship marketing and so important to the key customers (in all staff-related questions, in case of behavior, knowledge and proficiency, the customers expressed a degree of satisfaction higher than $70 \%$ ), therefore banks should have special programs to train and empowerment the staff to meet the key customers appropriately. Moreover the branch managers should receive necessary training to identify and maintain the key customers. The branch manager should cleverly identify the social networks among the key customers and take necessary actions to maintain and reinforce these networks. Assigning special counters to the key customers in the branch, providing banking services for the customers out of turn, and providing special check books and unusual extra services and as a result, the omission of trivial costs and installment delay fine should be taken into consideration. However note that based on the moral prism of Saderat bank and the equality of customers, providing special services for key customers should be done with care and delicacy in a way not to arouse tension or dissatisfaction in other customers. To this aim it's suggested that by using new technologies the digital calling systems be designed in a way to identify the key customer and assign him the earliest turn. In addition, providing special facilities and services to use the non-attendance services in banks and applying new technologies like the Internet and Cell phone softwares would be efficient. In this regard we should note that the application of these technologies should be with much care and along with the maintenance of customers and reinforcement of their relationship with the bank. To this aim, assigning special budget to improve the branch's facilities, beautifying the place and increasing the ATM s would be useful.

\subsection{The factor of supervision on relationships}

It is recommended that in addition to the installation of a precise and orderly system assigned to complain and dissatisfactions, banks enable the staff to cleverly and solely identify and resolve the problems. This would prevent the potential conflicts which itself is one of the essential factors and basics of relationship marketing. It should be noted that, as the studies show, while the customers are dissatisfied with one out of four purchases,only less than $5 \%$ of dissatisfied customers complaint. Most customers prefer, instead of complaint, to have limited services and relationships (Cotler, 1984). Hence companies cannot investigate the dimensions of customer satisfaction based on the received complaints and should use more precise methods. In this regard, the branch manager should codify more precise programs and receive feedback from customers about banking affaires and staff's performance. 


\section{Suggestions for further studies in the field of relationship marketing}

1- Attention should be paid to select the study field since in most industries and professions; the administration of relationship marketing is not efficient. It should be mentioned that companies seems to need a combination of trade marketing approaches to manage their activities.

2- Unfortunately in the study of relationship marketing this fact is constantly neglected that due to the high costs of relationship marketing, they can not be accomplished for all customers. So the population selection should be done with enough care. The statistical population does not include all customers.

3- Before providing the questionnaire, the main variables, should be modified in accordance with the organization's culture. This may be accomplished through detailed interviews with bank managers and key customers as the important components of the relationship.

\section{References}

[1] A. Azar,M.Momeni,Statistikal and Its Application in Management vol 2,SAMT,7,Tehran,2004.

[2] J. Abbasi, "Evaluating the role of the relationship marketing on key customer satisfaction the case of MELAT bank of Tehran". MSc thesis, univercity of tehran, 2002

[3] K. Das, Relationship Marketing Research(1994-2006)An Academic literature Review and Classification, Marketing Intelligence \& Planning, 27, No. 3(2009) 326-363.

[4] A. J Fernandez-Gonzalez, and J. C. P Prado, Measurement and analysis of customer satisfaction: company practices in Spain and Portugal, International Journal of Productivity and Performance Management, 56, No. 5/6(2007)500-517.

[5] C. Gro"nroos, The relationshipmarketing process:communication, interaction, dialogue, value, Journal of Business \& Industrial Marketing, 19, No 2 ( 2004), 99-113.

[6] E,Gummesson. Return On Relationship(ROR).Journal of Business \& Industrial Marketing,19,NO.2(2004) 136-142.

[7] P.H.Kotler,Marketing Management,analysis,planing,implemeniation, and control,translated by B.forouzandeh,4,Isfahan-Iran,2005.

[8] M.momeni,A.F ghayoumi, Statistical Analaysis With SPSS,2009.

[9] N. O. Ndubisi, Relationship Marketing and Customer loyalty, Marketing Intelligence \& Planning, 25, No. 1,(2007) 98-106.

[10] F. Reichheld, and W. Sasser, Zero defects: quality comes to services, Harvard Business Review, Sept-Oct, (1990), $105-111$.

[11] S. Ryals and Knox,. Ucross -funcional Issues in Implemmention of RM Trough CRM, European Management Jornalvol,19 No 5(2001) 534542 .

[12] S. So and M. Speece, Perceptions of Relationship Marketing Among Account Managers Of Commercial Banks in a Chinese Environment, International Journal of Bank Marketing, 18, No. 7, (2000) 315-327.

[13] H. Vasudevan, S .S Gaur, and R. K. Shinde, Relational Switching Costs, Satisfaction and Aommitment A study in the Indian manufacturing context, Asia Pacific Journal of Marketing and Logistic,18, No. 4,(2006),342-353.

[14] G. Whyatt, and R. Koschek ,Implementing relationship marketing: supermarkets’ Perspectives, Marketing Intelligence \& Planning ,28, No. 5, (2010) 582-596. 